\title{
PENGARUH PEMBERIAN EKSTRAK ETANOL KULIT BUAH \\ RAMBUTAN (Nephelium lappaceum L.) TERHADAP KADAR KOLESTEROL TOTAL DARAH TIKUS PUTIH JANTAN GALUR Sprague-Dawley
}

\author{
Gita Susanti ${ }^{1}$, Sonni Bramantio ${ }^{2}$ \\ 1.Dosen Tetap STIK Siti Khadijah \\ Email:gita_xf@yahoo.com
}

\begin{abstract}
ABSTRAK
Hiperkolesterol adalah suatu kondisi dimana jumlah kolesterol di dalam darah melebihi batas normal $(150 \mathrm{mg} / \mathrm{dL})$. Penelitian ini dilakukan untuk mengamati pengaruh pemberian ekstrak etanol $96 \%$ kulit buah rambutan (Nephelium lappaceum L.) terhadap kadar kolesterol total darah tikus putih jantan galur Sprague-Dawley. Metode penelitian ini adalah pre and post test control group design. Tikus Sprague-Dawley jantan sebanyak 25 ekor dibagi sebanyak 5 kelompok perlakuan. Kelompok 1 (kontrol negatif) diberi aquadest, kelompok 5 (kontrol positif) diberi Gemfibrozil, sedangkan kelompok 2,3, dan 4 diberi ekstrak dengan dosis 125, 250, dan $500 \mathrm{mg} / \mathrm{KgBB}$. Sebelum diberi perlakuan, tikus diberi pakan tinggi lemak yang terdiri dari 150 gram pakan standar, 20 gram kuning telur puyuh dan 50 gram margarin. Pakan tinggi lemak diberikan selama 1 minggu. Hasil penelitian menunjukkan ekstrak etanol kulit buah rambutan dosis 125,250 , dan $500 \mathrm{mg} / \mathrm{KgBB}$ dapat menurunkan kolesterol sebesar 17,81\%, $34,98 \%$, dan $52,35 \%$. Data yang diperoleh dianalisis secara komputerisasi menggunakan One-Way ANOVA $\left(\mathrm{P}_{\text {Value }} \leq 0,05\right)$.
\end{abstract}

Kata kunci: Antihiperkolesterol, Nephelium lappaceum L., kulit buah rambutan.

\begin{abstract}
Hypercholesterol is a condition that quantity of cholesterol in blood exceed normal limits (>150 mg/dL). This research was done to observe the effect of $96 \%$ of ethanolic extract of rambutan fruit (Nephelium lappaceum L.) peel to decrease total blood cholesterol level of Sprague-Dawley strain male white rats. This research method is the pre and post test control group design. Twenty fiveSprague-Dawley strain male white rats were divided into 5 groups. Group 1 (negative control) be given aquadest, group 5 (positive control) be given Gemfibrozile, whereas group 2, 3, and 4 treated by $96 \%$ of ethanolic extract of rambutan fruit peel with a dose of 125,250 , and $500 \mathrm{mg} / \mathrm{KgBW}$ respectively. Before rats given the treatments, the rats be given high cholesterol food consisting 150 gram standard feed, 20 gram quail egg yolk, and 50 gram margarine. High cholesterol food was given for one week. The result showed that the $96 \%$ of ethanolic extract of rambutan fruit (Nephelium lappaceum L.) peel with a dose of 125,250 , and $500 \mathrm{mg} / \mathrm{KgBW}$ have antihypercholesterol activity 17,81\%, 34,98\%, and $52,35 \%$. Data were analyzed using computer program One-Way ANOVA test $\left(\mathrm{P}_{\text {Value }} \leq 0,05\right)$.
\end{abstract}

Keywords: Antihypercholesterol, Nephelium lappaceum L., rambutan fruit peel. 


\section{PENDAHULUAN}

Hiperkolesterol adalah suatu kondisi jumlah kolesterol di dalam darah melebihi batas normal. Kolesterol merupakan unsur penting dalam tubuh yang diperlukan untuk mengatur proses kimiawi di dalam tubuh, tetapi kolesterol dalam jumlah tinggi bisa menyebabkan terjadinya aterosklerosis yang akhirnya akan berdampak pada penyakit jantung koroner (PJK) (Rebecca, dkk., 2014).

Data WHO

(WorldHealth

Organization) tahun 2015 memperlihatkan Penyakit Jantung Koroner (PJK) sebagai penyebab kematian utama di dunia, diperkirakan sekitar 8,7 juta orang di dunia meninggal karenanya (WHO, 2015). Berdasarkan data Riskesdas (Riset Kesehatan Dasar) tahun 2013, proporsi penduduk Indonesia dengan kadar kolesterol di atas normal lebih tinggi pada perempuan $(39,6 \%)$ dibandingkan pada laki-laki $(30,0 \%)$ dan di daerah perkotaan lebih tinggi daripada daerah pedesaan (Depkes, 2013).

Hiperkolesterol dapat terjadi karena faktor genetik serta gaya hidup (life style) yang tidak sehat, mulai dari pola makan yang tidak seimbang sampai kurangnya aktivitas olahraga. Kadar kolesterol yang tinggi dapat disebabkan oleh sintesis kolesterol dan penyerapan kolesterol yang tinggi dan juga karena konsumsi makanan tinggi lemak dan karbohidrat (Sudha, dkk., 2009; Hernawati dkk., 2013).

Saat ini banyak sekali beredar di pasaran, obat-obatan untuk penurun kolesterol baik obat alami maupun obat sintetis. Namun karena penggunaan obat modern atau sintetis memiliki efek samping seperti retensi air dengan hiponatremi dan gangguan gastrointestinal (Krentz and Bailey, 2005), maka kecenderungan masyarakat saat ini lebih memilih obat alami karena obat alami diyakini lebih aman, murah dan mudah ditemukan bahan bakunya di sekitar masyarakat dibanding obat sintetis (Lin, 2010). Fenomena ini menjadi perhatian khusus dikalangan para peneliti bahan alam. Salah satu tumbuhan yang dapat digunakan untuk menurunkan kadar kolesterol total darah adalah rambutan. $\begin{array}{lll}\text { Rambutan (Nepheliumlappaceum L.) } & \end{array}$ merupakan salah satu spesies tumbuhan yang mengandung banyak metabolit sekunder yang saling bersinergis dalam memberikan efek (Bone and Mills, 2013). Kulit buah rambutan mengandung senyawa-senyawa metabolit sekunder golongan tanin, polifenol, dan saponin (Thitilertdecha, dkk., 2008). Salah satu metabolit sekunder yang terkandung dalam kulit buah (perikarp) rambutan yang dapat menurunkan kadar kolesterol total darah adalah saponin (Murray, dkk., 2003). 
Selama ini masyarakat menganggap hanya daging buah rambutan saja yang dapat dimanfaatkan untuk dikonsumsi, sedangkan kulit buahnya dibuang dan hanya dijadikan limbah. Penelitian tentang kulit buah rambutan sebagai obat antihiperkolesterol telah dilakukan oleh beberapa peneliti sebelumnya. Salah satunya menurut penelitian (Muhtadi, dkk., 2013) yang menyatakan bahwa ekstrak etanolkulit buah rambutan dengan dosis 125, 250, dan $500 \mathrm{mg} / \mathrm{KgBB}$ memiliki efek terhadap penurunan kadar kolesterol total darah pada tikus putih.

Berdasarkan latar belakang di atas, peneliti ingin membuktikan manfaat kulit buah rambutan terhadap penurunan kadar kolesterol total darah tikus putih jantan galur Sprague-Dawley yang diberi makanan tinggi kolesterol, dengan menggunakan obat penurun kolesterol yang umum dipakai di masyarakat, yaitu gemfibrozil sebagai kontrol positif.

\section{METODOLOGI PENELITIAN}

Penelitian ini termasuk dalam jenis penelitian yang bersifat eksperimental dengan menggunakan metode pre and post test control group design. Variabel bebas pada penelitian ini meliputi seri dosis ekstrak etanol kulit buah rambutan sedangkanvariabel terikat pada penelitian ini adalah kadar kolesterol total dalam darah tikus.

Bahan-bahan yang digunakan dalam penelitian ini adalahkulit buah rambutan (Nephelium lappaceum L.), aquadest steril, etanol 96\%, CMC-Na 0,5\%, pakan standar (pellet), kuning telur puyuh, margarin dan gemfibrozil.

Alat-alat yang digunakan dalam penelitian ini adalah timbangan, kain hitam, sikat, pisau, blender, kertas saring, rotary evaporator, heating mantle, waterbath,volume pipet, sonde oral, alatalat gelas, holder,dan alat serta strip cek kolesterol EasyTouch ${ }^{\circledR} \mathrm{GCU} \quad$ MultiFunction Monitoring System.

Kulit buah rambutan (Nephelium lappaceum L.) diambil di Jl. Letnan Amir Hamzah 2 No. A 2862 di Kecamatan Pasar Lama, Kabupaten Lahat. Kulit buah rambutan kemudian dibersihkan di bawah air yang mengalir, dirajang tipis, dikeringkan, kemudian diserbuk dengan blender.

Ekstraksi dilakukan dengan merendam 2000 gram serbuk simplisia kering kulit buah rambutan dengan 4 liter pelarut etanol 96\%. Filtratkemudian diambil dan disaring dengankertas saring selama 3 x 24 jam. Filtrat lalu dikumpulkan dan penyari diuapkan kembali menggunakan rotary evaporator sehingga diperoleh ekstrak kental etanol kulit buah rambutan. Ekstrak kental 
tersebut dikeringkan menggunakan penangas air (waterbath). Rendemen ditimbang bobot keringnya dan dicatat sebagai bobot ekstrak etanol.

Pemberian pakantinggi lemak dilakukan selama 7 hari. Pakan tinggi lemak terdiri dari 150 grampakan standar (pellet), 20 gram kuning telur puyuh,dan 50 gram margarin. Cara membuatnya, yaitu margarin dipanaskan hingga leleh kemudian semua bahan dicampur dan diaduk sampai rata. Pakan tinggi lemak diberikan sebanyak 30 gram/hari.

Hewan uji yang digunakan yaitu tikus putih galur Sprague-Dawley sebanyak 25 ekor yang dibagi menjadi 5 (lima) kelompok. Setiap kelompok terdiri dari 5 (lima) ekor tikus yang dibagi secara purposive sampling. Semua hewan uji diadaptasikan terlebih dahulu selama 7 (tujuh) hari dalam kondisi di laboratorium dengan diberi pakan standar (pellet) dan minum secara ad libitum. Sebelum pemberian pakan tinggi lemak, terlebih dahulu dilakukan pengukuran kadar awal kolesterol total (kadar pre test). Pengukuran kadar kolesterol total diukur sebelum diberi pakan tinggi lemak, 1 minggu setelah diberi pakan tinggi lemak dan 1 minggu setelah pemberian ekstrak. Sampel darah tikus diambil dengan cara memotong sedikit ujung ekor.

Pakan tinggi lemak diberikan selama 1 minggu sedangkan perlakuan pemberian ekstrak dilakukan selama 1 minggu (setelah hiperkolesterolemia dengan kadar kolesterol total $\geq 150$ $\mathrm{mg} / \mathrm{dL}$ ) pada semua kelompok:

Kelompok 1 : Aquadest (Kontrol Negatif)

Kelompok 2 :Gemfibrozil 300 mg/KgBB (KontrolPositif)

Kelompok 3 : Ekstrak etanol kulit buah rambutan dosis $125 \mathrm{mg} / \mathrm{KgBB}$ perOral Kelompok 4 : Ekstrak etanol kulit buah rambutan dosis $250 \mathrm{mg} / \mathrm{KgBB}$ perOral Kelompok 5 : Ekstrak etanol kulit buah rambutan dosis $500 \mathrm{mg} / \mathrm{KgBB}$ per Oral

\section{HASIL DAN PEMBAHASAN}

Sebanyak 2 kilogram (2000 gram) sampel segar kulit buah rambutan (Nephelium lappaceum L.)yang dimaserasi dengan pelarut etanol 96\%, diperoleh ekstrak etanol kental kulit buah rambutan (Nephelium lappaceum L.) sebanyak 95,4 gram sehingga rendemen yang diperoleh sebesar $4,77 \%$ (b/b).

$$
\begin{aligned}
& \% \text { Rendemenekstrak }=\frac{\text { Bobot } \text { Total Ekstrak }}{\text { Bobot Serbuk } \text { Total }} \times 100 \% \\
& \% \text { Rendemen ekstrak }=\frac{95,4 \text { gram }}{2000 \mathrm{gram}} \times 100 \% \\
& \% \text { Rendemen Ekstrak }=4,77 \%
\end{aligned}
$$

Tabel A. Hasil persentase penurunan kadar kolesterol total darah tikus putih jantan galur Sprague-Dawley

\begin{tabular}{|l|l|l|l|l|c|}
\hline No. & $\begin{array}{l}\text { Perla } \\
\text { kuan }\end{array}$ & $\begin{array}{l}\text { Pre- } \\
\text { test }\end{array}$ & $\begin{array}{l}\text { Induk } \\
\text { si }\end{array}$ & Ekstrak & $\begin{array}{l}\text { \%Penur } \\
\text { unan }\end{array}$ \\
\hline 1. & Kontr & 323,20 & 353,60 & $370,40 \pm$ & - \\
& ol (-) & \pm & \pm & 41,89 & \\
& (Aqu & 47,19 & 42,97 & & \\
\hline
\end{tabular}




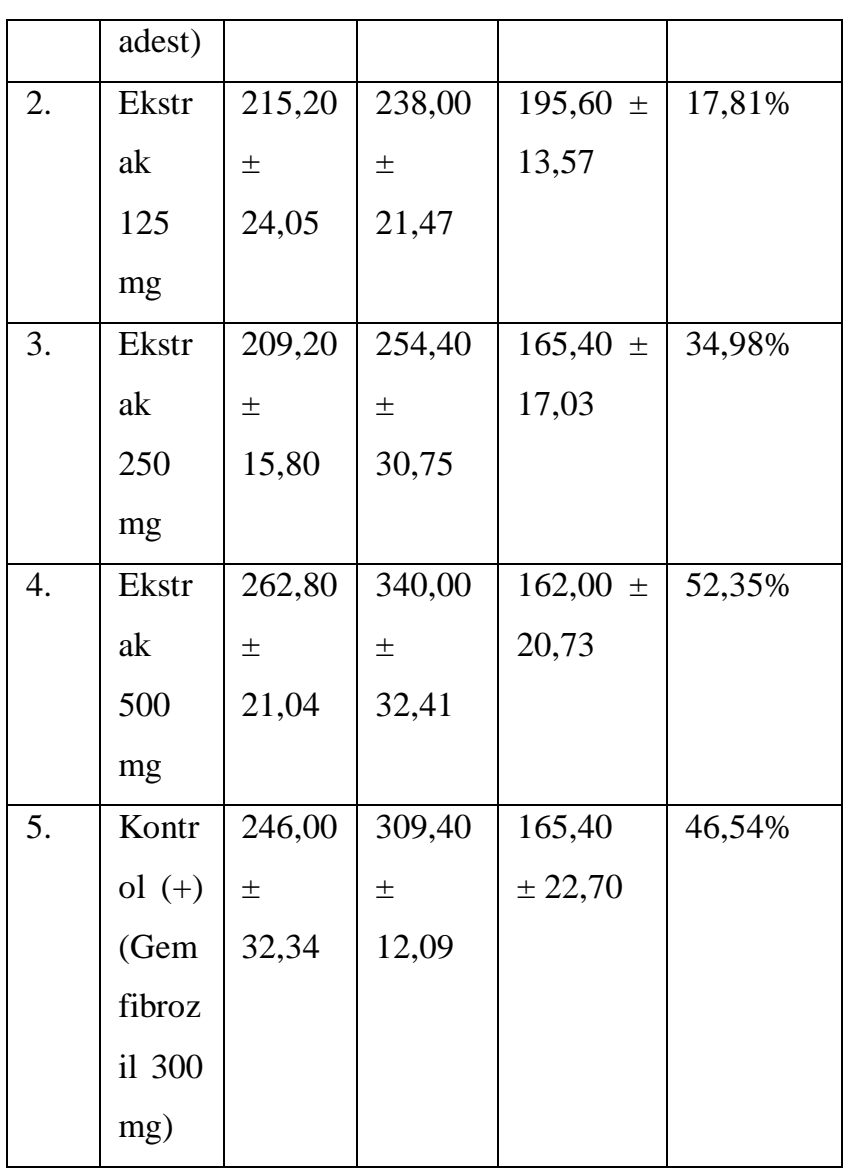

Berdasarkan tabel di atas, ekstrak etanol kulit buah rambutan (Nephelium lappaceum L.) dengan variasi dosis yang paling kecil, yaitu $125 \mathrm{mg} / \mathrm{KgBB}$ sudah memiliki aktivitas dalam menurunkan kadar kolesterol total dalam darah tikus, yaitu sebesar $17,81 \%$. Sedangkan, ekstrak etanol kulit buah rambutan (Nephelium lappaceum L.) dengan variasi dosis yang paling besar, yaitu $500 \mathrm{mg} / \mathrm{KgBB}$ memiliki aktivitas dalam menurunkan kadar kolesterol total dalam darah tikus paling besar, yaitu sebanyak 52,35\%, lebih kuat bila dibandingkan dengan kontrol positif (Gemfibrozil $300 \mathrm{mg} / \mathrm{KgBB}$ ) yang hanya memiliki aktivitas dalam menurunkan kadar kolesterol total dalam darah tikus sebesar 46,54\%. Dengan demikian, pemberian ekstrak etanol kulit buah rambutan (Nephelium lappaceum L.) dapat menurunkan kadar kolesterol total dalam darah tikus putih jantan galur Sprague-Dawley.

Sebelum dilakukan uji One-Way ANOVA, terlebih dahulu dilakukan uji homogenitas (Levene test) dengan tujuan untuk melihat homogenitas data penurunan jumlah kolesterol total dalam darah tikus, dengan ketentuan apabila $\mathrm{P}_{\text {Value }} \geq 0,05$ maka data penurunan jumlah kolesterol total dalam darah tikus bervariasi homogen sedangkan jika $\mathrm{P}_{\text {Value }} \leq 0,05$ artinya data bervariasi tidak homogen.

Tabel B. Uji Homogenitas ANOVA Data Jumlah Penurunan Kadar Kolesterol Total

Test of Homogeneity of Variances

\begin{tabular}{|l|r|r|r|r|}
\hline & $\begin{array}{r}\text { Levene } \\
\text { Statistic }\end{array}$ & df1 & df2 & \multicolumn{2}{|c|}{ Sig. } \\
\hline Sebelum & 2.831 & 4 & 20 & .052 \\
Induksi & 3.187 & 4 & 20 & .035 \\
Ekstrak & 4.314 & 4 & 20 & .011 \\
\hline
\end{tabular}

Berdasarkan tabel di atas, diketahui bahwa nilai $\mathrm{P}_{\text {Value pada }} \mathrm{H}_{0}$ (sebelum perlakuan) adalah 0,052 artinya data penurunan jumlah kolesterol total dalam darah tikus bervariasi homogen. Sedangkan, nilai $\mathrm{P}_{\text {Value }}$ pada $\mathrm{H}_{7}$ (induksi pakan) dan $\mathrm{H}_{14}$ (pemberian ekstrak) adalah 
0,035 dan 0,011 artinya data penurunan jumlah kolesterol total dalam darah tikus bervariasi tidak homogen. Kesimpulannya dikarenakan ada 2 (dua) kelompok data yang tidak homogen maka dapat dikatakan kelompok data di atas tidak memenuhi syarat untuk dilakukan uji One-Way ANOVA, sehingga uji lanjutan diteruskan dengan Bonferroni test.

Hasil perbandingan data statistik secara komputerisasi menggunakan program IBM SPSS Statistics 22 for Windows pengaruh pemberian ekstrak etanol kulit buah rambutan dapat dilihat pada tabel B.

Tabel C. Hasil Perbandingan Data Statistik Pengaruh Pemberian Ekstrak Etanol Kulit Buah Rambutan (Nephelium lappaceum L.)

\begin{tabular}{|c|c|c|c|}
\hline Variabel & Perlakuan & $\begin{array}{c}\text { Perlakuan } \\
\text { lainnya }\end{array}$ & $\mathbf{P}_{\text {Value }}$ \\
\hline \multirow[t]{5}{*}{ Ekstrak } & $\begin{array}{l}\text { Kontrol } \\
\text { Negatif }\end{array}$ & $\begin{array}{l}\text { Ekstrak } \\
125 \mathrm{mg}\end{array}$ & 0,000 \\
\hline & (Aquadest) & $\begin{array}{l}\text { Ekstrak } \\
250 \mathrm{mg}\end{array}$ & 0,000 \\
\hline & & $\begin{array}{l}\text { Ekstrak } \\
500 \mathrm{mg}\end{array}$ & 0,000 \\
\hline & & $\begin{array}{c}\text { Kontrol (+) } \\
\text { (Gemfibrozil) }\end{array}$ & 0,000 \\
\hline & Ekstrak125 & Ekstrak & 0,727 \\
\hline
\end{tabular}

\begin{tabular}{|c|c|c|}
\hline \multirow[t]{3}{*}{$\mathrm{mg}$} & $250 \mathrm{mg}$ & \\
\hline & $\begin{array}{l}\text { Ekstrak } \\
500 \mathrm{mg}\end{array}$ & 0,478 \\
\hline & $\begin{array}{c}\text { Kontrol (+) } \\
\text { (Gemfibrozil) }\end{array}$ & 0,727 \\
\hline \multirow[t]{2}{*}{$\begin{array}{c}\text { Ekstrak250 } \\
\text { mg }\end{array}$} & $\begin{array}{l}\text { Ekstrak } \\
500 \mathrm{mg}\end{array}$ & 1,000 \\
\hline & $\begin{array}{c}\text { Kontrol (+) } \\
\text { (Gemfibrozil) }\end{array}$ & 1,000 \\
\hline $\begin{array}{c}\text { Ekstrak500 } \\
\mathrm{mg}\end{array}$ & $\begin{array}{c}\text { Kontrol (+) } \\
\text { (Gemfibrozil) }\end{array}$ & 1,000 \\
\hline
\end{tabular}

Berdasarkan tabel di atas, diketahui bahwa kadar kolesterol total dalam darah tikus seluruh kelompok uji variasi dosis ekstrak dan kontrol positif pada $\mathrm{H}_{14}$ berbeda secara bermakna $\left(\mathrm{P}_{\text {Value }} \leq 0,05\right)$ dengan kontrol negatif karena kelompok uji variasi dosis ekstrak dan kontrol positif telah mengalami penurunan kolesterol total dalam darah tikus, sedangkan kontrol negatif justru mengalami kenaikan kolesterol total dalam darah tikus.

\section{SIMPULAN DAN SARAN}

Ekstrak etanol kulit buah rambutan (Nephelium lappaceum L.) pada dosis 125, 250, dan $500 \mathrm{mg} / \mathrm{KgBB}$ memiliki efek antihiperkolesterol dengan nilai persentase penurunan kolesterol sebesar 17,81\%, 
$34,98 \%$, dan $52,35 \%$ dimana semakin tinggi variasi dosis yang diberikan maka persentase penurunan kadar kolesterol total dalam darah juga akan semakin besar.

Saran untuk penelitian selanjutnya diharapkan dilakukan penelitian lanjutan mengenai efek kulit buah rambutan terhadap penurunan berat badan.

\section{DAFTAR PUSTAKA}

Badan Penelitian dan Pengembangan Kesehatan Kementerian RI. 2013. Riset Kesehatan Dasar (Riskesdas). Diakses: 29 April 2018, dari http://www.depkes.go.id/resources/dow nload/general/Hasil\%20Riskesdas\%202 013.pdf.

Bone, K. \& Mills, S. 2013. Principles and Practice of Phytotherapy. $2^{\text {nd }}$ Ed. New York: Churchill Livingstone Elsevier.

Hernawati, W. Manali, Suprayogi, A. \& Astuti, D. A. 2013. Perbaikan Parameter Lipid Darah Mencit Hiperkolesterolemia dengan Suplemen Pangan Bekatul. MKB.

Krentz, A. J. \& Bailey, C. J. 2005. Oral Diabetic Agents Current Role in Type 2 Diabetes Mellitus. Review Article.

Lin, B. F. 2010. Isolation and Identification of Bioactive Compounds in Andrographis paniculata (Chuanxinlian). Chinese Medicine.
Muhtadi, Haryoto, Sujono, Tanti Azizah, Indaryudha, Peni \& Suhendi, Andi. 2013. Pengembangan Potensi Ekstrak Kulit Buah Rambutan sebagai Bahan Obat Herbal Antihiperkolesterol. Biomedika.

Murray, R. K., Granner, D. K. Mayes, P. A. \& Rodwell, V. W. 2003. Biokimia Harper. $25^{\text {th }}$ Ed. Jakarta: EGC.

Rebecca, Vanessa, Purwijantiningsih, Lorensia Maria Ekawati \& Aida, Yuniarti. 2014. Pemanfaatan Minuman Serbuk Instan Kayu Manis (Cinnamomum burmanii BI.) untuk Menurunkan Kadar Kolesterol Total Darah pada Tikus Putih (Rattus norvegicus). Fakultas Teknobiologi, Universitas Atma Jaya Yogyakarta.

Sudha, M. R., Prashant, C., Kalpana, D., Sekhar, B. \& Kaiser, J. 2009. Probiotics as Complementary Therapy for Hypercholesterolemia. Biology and Medicine. Volume 1.

Thitilertdecha, N., Teerawutgulrag, A., Rakariyatham, N. 2008. Antioxidant and Antibacterial Activities of Nephelium lappaceum L. extracts. Food Science and Technology, Elsevier.

WHO. 2015. Library CataloguingPublication Data. Heart: Technical Package for Cardiovascular Disease Management in Primary Health Care. WHO Press: Switzerland. 